\title{
Novel mutation in MCT8 gene in a Brazilian boy with thyroid hormone resistance and severe neurologic abnormalities
}

\author{
Mutação nova do gene MCT8 em menino brasileiro com \\ resistência ao hormônio tireioidiano e neuropatia grave
}

Hamilton Cabral de Menezes Filho', Suemi Marui' ${ }^{2}$ Thais Della Manna', Ester Saraiva Brust², Vanessa Radonsky', Hilton Kuperman', Vaê Dichtchekenian', Nuvarte Setian', Durval Damiani'

${ }^{1}$ Pediatric Endocrinology Unit, Instituto da Criança, Hospital das Clínicas, Faculdade de Medicina da Universidade de São Paulo $(\mathrm{ICr}$ HC-FMUSP), São Paulo, SP, Brazil

${ }^{2}$ Thyroid Unit, Laboratory of Molecular Genetics and Hormones (LIM-25), Division of Endocrinology, FMUSP, São Paulo, SP, Brazil
Correspondence to: Hamilton Cabral de Menezes Filho Rua Joinville, 637, ap. 701 04008-011 - São Paulo, SP, Brazil hamiltoncm@uol.com.br

Received on Jul/30/2010 Accepted on Dec/14/2010

\begin{abstract}
SUMÁRIO
O MCT8 é um transportador celular de hormônios tireoidianos, importante para sua ação e metabolização. Relatamos o caso de um menino com a nova mutação inativadora 630insG no éxon 1 do MCT8. 0 paciente caracterizou-se por grave comprometimento neurológico (inicialmente com hipotonia global, evoluindo com hipertonia generalizada), crescimento normal nos dois primeiros anos de vida, reduzido ganho ponderal e ausência dos sinais e sintomas típicos de hipotireoidismo. A sua avaliação sérica revelou elevação doT3, redução doT4 total e livre e TSH levemente aumentado. 0 tratamento com levotiroxina melhorou o perfil hormonal tireoidiano, mas não modificou o quadro clínico do paciente. Esses dados reforçam o conceito de que o papel do МСТ8 é tecido-dependente: enquanto os neurônios são altamente dependentes do MCT8, o osso, o tecido adiposo, o músculo e o fígado são menos dependentes do MCT8 e, portanto, podem sofrer as consequências da exposição a níveis séricos elevados de T3. Arq Bras Endocrinol Metab. 2011;55(1):60-6
\end{abstract}

\section{SUMMARY}

MCT8 is a cellular transporter of thyroid hormones important in their action and metabolization. We report a male patient with the novel inactivating mutation 630ins $\mathrm{G}$ in the coding region in exon 1 of MCT8. He was characterized clinically by severe neurologic impairment (initially with global hypotonia, later evolving with generalized hypertonia), normal growth during infancy, reduced weight gain, and absence of typical signs and symptoms of hypothyroidism, while the laboratory evaluation disclosed elevated T3, low total and free T4, and mildly elevated TSH serum levels. Treatment with levothyroxine improved thyroid hormone profile but was not able to alter the clinical picture of the patient. These data reinforce the concept that the role of MCT8 is tissue-dependent: while neurons are highly dependent on MCT8, bone tissue, adipose tissue, muscle, and liver are less dependent on MCT8 and, therefore, may suffer the consequences of the exposition to high serum T3 levels. Arq Bras Endocrinol Metab. 2011;55(1):60-6

\section{INTRODUCTION}

I odothyronine deiodinases are capable of activating or inactivating thyroid hormones $(\mathrm{TH})(1)$. Type 2 deiodinase (D2) removes an outer ring iodine atom, allowing the conversion of tetraiodothyronine (T4, or thyroxine) into triiodothyronine (T3), the active form of TH (1). On the other hand, the inactivation of T4 to reverse $\mathrm{T} 3$ (rT3) and of $\mathrm{T} 3$ to $\mathrm{T} 2$ depends on the internal ring deiodination by type 3 iodothyronine deiodinase (D3). Type 1 iodothyronine deiodinase (D1) catalyzes the removal of inner or outer ring iodine atoms and therefore generates T3, rT3, or T2, depending on the substrate (1). In humans most circulating T3 arises from $\mathrm{T} 4$ by the actions of $\mathrm{Dl}$ in the liver and kidney, although D2 in the skeletal muscle also contributes (1). Hepatic Dl is involved in the clearance of $\mathrm{rT} 3$ into 
T2, while D2 controls the intracellular concentration of T3 (1). D2 is responsible for the local generation of T3 when there is deprivation of T4, protecting vital organs (like the brain, for example) during periods of hypothyroidism (1). D3 is the only enzyme capable of degrading $\mathrm{TH}$ with an important role in the negative control of tissue and serum T3 levels (2).

The biological activity of TH is related to intracellular T3 concentration, which depends on the concentration of circulating T4 and T3, the activity of deiodinases D1 and D2, and the activity of transporters responsible for the influx and/or efflux of T3 and T4 (2). The monocarboxylate transporter 8 (MCT8) is an active transporter highly specific for $\mathrm{TH}$ present in different tissues, including the brain, where it is expressed specifically by $\mathrm{TH}$-sensitive neuronal populations (2). Friesema and cols. were the first to demonstrate that rat MCT8 facilitates the transport of iodothyronines into Xenopus laevis oocytes injected with the mRNA coding for this transporter (3). Subsequent studies demonstrated the role of MCT8 in the TH transport in human tissues, particularly the brain $(4,5)$. Later, Friesema and cols. showed that human MCT8 stimulates cellular uptake of T4 and T3, but does not seem to be important for rT3 and T2 transportation (6). Importantly, they also demonstrated that MCT8 increases iodothyronine metabolism by deiodinases, a direct evidence that MCT8 increases the intracellular availability of these substrates (6). MCT8 and D2 seem to act synchronically since the treatment with T4 of cells co-expressing MCT8 and D2 results in increased T3 production and hormone responsiveness (1).

The expression of MCT8 in the choroid plexus and in large capillaries indicates that it is involved in the transport of $\mathrm{TH}$ across the blood-brain barrier and the blood-cerebrospinal fluid barrier (2). MCT8 is present in neurons and astrocytes of the paraventricular and infundibular nuclei, and in tanycytes located in the central lining of the third ventricle (these cells are in close contact with the cerebrospinal fluid, hypothalamus and median eminence and probably supply T3 to the central nervous system) (2). In neurons, MCT8 is important for the uptake of T3 produced from T4 in neighboring astrocytes that express $\mathrm{D} 2$. Neurons are the primary targets for $\mathrm{TH}$ action in the developing brain, and mutations in gene MCT8 deprive neurons of essential T3 and result in psychomotor retardation (2). The action of T3 on neurons is controlled by the local inactivation of T3 by D3. Therefore a defect in MCT8 also reduces the inactivation of $\mathrm{T} 3$, resulting in increased serum T3 levels (2).

The MCT8 gene consisting of six exons is located on the $\mathrm{X}$ chromosome $(\mathrm{Xq13.2})$ and codes for a protein of 539 or 613 aminoacids depending on which of the two possible translation start sites is used. MCT8 has 12 putative transmembrane domains (2). The human MCT8 gene was cloned in 1994 (2).

The inactivating mutations of MCT8 are associated to a severe neurologic dysfunction and high serum T3, that constitute the Allan-Herndon-Dudley syndrome (MIM 309600) (7). In addition to mutations in thyroid hormone receptor, the inactivating mutations of MCT8 constitute another cause of TH resistance (2).

In this article we describe a new MCT8 mutation identified on a male patient with severe neurological impairment and high serum T3 concentration.

\section{SUBJECT AND METHODS}

A male patient aged 12.25 years was first evaluated at our Unit of Pediatric Endocrinology when he was 9 months old. The patient was referred to us due to neurologic delay, generalized hypotonia, strabismus, brain malformation, and abnormal thyroid profile. His mother was 22 years old when she became pregnant. Pregnancy and delivery were uneventful. Gestational age was of 40 weeks and the Apgar score in the first and fifth minutes was respectively 8 and 9 . His birth weight $(3096 \mathrm{~g})$, body length $(51 \mathrm{~cm})$, and head circumference $(35 \mathrm{~cm})$ were normal. His parents are healthy and nonconsanguineous. His two brothers are healthy. There was no familial history of neurological impairment or of thyroid diseases. His neurological development was impaired since the first months of life: the patient has never been able to control his head or to sit, showed few reactions to external stimuli and little communication with his parents and medical personnel. On the other hand, he could breast-feed efficiently. His parents described that he slept during the day and was awake at night what suggested a disruption of the wake-sleep cycle. His movements were uncoordinated. The auxological evaluation at the age of 9 months showed normal body length $(74.5 \mathrm{~cm}$; + 0.89 SDS), poor weight gain $(9.0 \mathrm{~kg} ;-0.36 \mathrm{SDS})$, and normal head circumference $(46 \mathrm{~cm} ;+0.50$ SDS). The disproportion between his stature and weight resulted in a thin appearance. Physical exam showed asymmetry of the skull. In spite of a global hypotonia his upper right limb was 
hypertonic. No goiter was found, nor were any clinical characteristic of hypothyroidism noted. His cardiac rhythm was normal (76 bpm).

The global hypotonia noted during the first year of life gave rise to a generalized hypertonia with spastic quadriplegia. During his follow-up a severe visual impairment was identified. The patient evolved with a crisis first noted when he was 2 years old characterized by fixed and deviated eyes, deviation of his head, loss of consciousness, and hypertonia of all four limbs. The crises were provoked by emotional stress or by crying. Initially, the crises occurred two to three times per week but the frequency increased up to two to three times per day, which prompted the introduction of anticonvulsant therapy.

While his growth was normal during the first 20 months of life (stature at 20 months $=85.0 \mathrm{~cm} ;+0.33$ SDS), his weight-gain worsened continuously (weight at 20 months $=10.0 \mathrm{~kg} ;-1.82$ SDS). However, from 20 months on both growth and weight-gain were impaired. The first teeth eroded after 16 months of life.

His first thyroid evaluation, performed when he was 7 months old, disclosed high serum T3, reduced total and free T4, and TSH mildly increased (Table 1).

As clinical and hormonal features suggested a mutation of MCT8 a molecular study was performed on the patient, his mother, and his brother, after informed consent was obtained from his parents. Genomic DNA was isolated from peripheral blood according to standard procedures (8). PCR from all exons were amplified individually, as previously described and directly sequenced (ABI PRISM 3130 xl, Perkin-Elmer Applied Biosystems, Foster City, California, USA) (5).

\section{RESULTS}

In the neonatal period, screening for congenital hypothyroidism was normal. Laboratory evaluations ruled out cytomegalovirus infection, infectious mononucleosis, syphilis, toxoplasmosis, rubella, and HIV. There was mild anemia $(\mathrm{Hb}=10.6 \mathrm{~g} / \mathrm{dL}$; mean corpuscular volume $=74.3 \mathrm{fL}$ ).

Curiously, high titles of thyroglobulin antibodies $(1125.3 \mathrm{IU} / \mathrm{mL})$ were detected when he was 0.87 years old. Subsequently serum levels of antithyroid antibodies (thyroglobulin and thyroperoxidase antibodies) were normal but since the age of 8.3 years they have increased again.

Thyroid scintigraphy with ${ }^{131}$ I showed a gland with normal position, size and morphology, while scintigraphy with ${ }^{99 \mathrm{~m}} \mathrm{Tc}$ identified a normal captation after 2 hours (13\%; normal range: $8 \%-18 \%)$, and a reduced captation after 24 hours (6\%; normal range: $20 \%-48 \%)$.

A brain computed tomography showed reduced ventricles and a bilateral posterior hypodense extra-axial collection. When he was 7 years old, an electroencephalogram revealed irregular slow-wave activity compatible with diffuse brain suffering.

Re-evaluation of thyroid function when he was 1.47 and 1.64 years old, identified high serum T3, low total and free T4, and TSH values progressively higher ( $\mathrm{Ta}$ ble 1). The increase of serum TSH during his follow-up prompted the introduction of levothyroxine at a dose of $50.0 \mu \mathrm{g} / \mathrm{m}^{2} /$ day, posteriorly increased to $94.9 \mu \mathrm{g} /$ $\mathrm{m}^{2} /$ day (corresponding to $3.75 \mu \mathrm{g} / \mathrm{kg} /$ day when he was 11.5 years old). Treatment with levothyroxine was associated to improvement in thyroid function with normalization of serum T3, progressive increase of free T4, normalization of $\mathrm{TSH}$, and maintenance of low total T4, as showed by the laboratory evaluation results obtained at the ages of 8.75 and 11.6 years (Table 1 ). On the other hand, it was not easy to evaluate the clinical effects of the treatment due to the patient's severe neurologic impairment. Meanwhile we noticed that during the 10.5 years of treatment with levothyroxine there was a gradual worsening of the weight deficit from -1.82 to -5.09 SDS.

Table 1. Summary of the findings of thyroid function tests performed at different ages

\begin{tabular}{|c|c|c|c|c|}
\hline Age & Total T3 (ng/dL) & Total T4 ( $\mu \mathrm{g} / \mathrm{dL})$ & Free T4 (ng/dL) & TSH $(\mu \mathrm{U} / \mathrm{mL})$ \\
\hline 7 months old & $285.3(100.0-260.0)$ & $4.9(7.0-15.0)$ & $0.50(0.7-1.9)$ & $4.50(0.25-4.0)$ \\
\hline 1.47 years old & $337.0(70.0-200.0)$ & $3.4(6.4-13.3)$ & $0.50(0.6-1.54)$ & $6.80(0.5-4.2)$ \\
\hline 1.64 years old & $275.0(105.0-269.0)$ & $4.1(5.6-10.0)$ & $0.50(0.7-1.8)$ & $9.40(0.5-5.0)$ \\
\hline 8.75 years old* & $235.0(94.0-241.0)$ & $3.3(6.4-13.3)$ & $0.67(0.7-1.5)$ & $2.67(0.6-6.3)$ \\
\hline 11.6 years old & $166.0(94.0-241.0)$ & $5.5(6.4-13.3)$ & $0.85(0.7-1.5)$ & $1.29(0.5-4.9)$ \\
\hline
\end{tabular}

Normal reference ranges in parenthesis.

* : At these ages the patient received treatment with levothyroxine. 
Lipid profile was evaluated when the patient was 8.75 years old. At that moment he was treated with levothyroxine $\left(33 \mu \mathrm{g} / \mathrm{m}^{2} /\right.$ day $)$ and his thyroid function was characterized by $\mathrm{T} 3$ in the upper limit of the normal range, low total and free T4, and normal TSH (Table 1$)$. Lipid profile was normal: total cholesterol $=$ $180 \mathrm{mg} / \mathrm{dL}, \mathrm{LDL}=101 \mathrm{mg} / \mathrm{dL}, \mathrm{HDL}=44 \mathrm{mg} / \mathrm{dL}$ and triglyceride $=62 \mathrm{mg} / \mathrm{dL}$.

Molecular study of the patient identified the insertion of a G nucleotide at the position 630 (630insG) in the coding region in exon 1 of MCT8. The mutation caused a frameshift in exon 1 and truncated the protein at codon 240, as shown in figure 1 . His mother is heterozygous for this mutation and his asymptomatic brother does not carry the mutation. As this insertion has not been seen in 50 healthy control men, polymorphism was excluded.

Thyroid function serum evaluation of his mother, heterozygous for the mutation and asymptomatic, showed normal TSH $(1.82 \mu \mathrm{U} / \mathrm{mL}), \mathrm{T} 3$ in the upper limit of normality (199 ng/dL; normal range: 70-200 ng/dL), normal T4 (7.1 $\mu \mathrm{g} / \mathrm{dL})$, and low free T4 $(0.63 \mathrm{ng} / \mathrm{dL}$; normal range: 0.7-1.5). Antithyroid antibodies were absent.

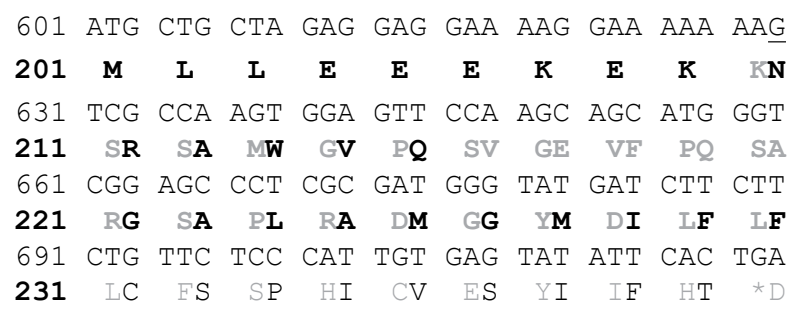

Figure 1. Nucleotide and amino acid sequences of human MCT8 and the alterations introduced by the mutation insG630 (underlined). Downstream of the $G$ insertion, the wild-type amino acid sequence is indicated in black and the mutant sequence in gray. The insertion results in a frame-shift with truncation of the protein at codon $240\left(^{*}\right)$.

\section{DISCUSSION}

TH have crucial roles in brain development including the control of cell proliferation, specification of neural and glial cell fate, migration and synaptogenesis (9). During hypothyroid states it is important that the intracellular concentration of $\mathrm{T} 3$, the active $\mathrm{TH}$, be maintained at a safe range, especially in vital organs like the brain. In the brain this is achieved by means of increased brain uptake of serum T3 through increased action of transporters like MCT8, increased conversion of T4 to T3 through increased action of D2 and decreased conversion of T3 to T2 through reduced action of D3 (9). These compensatory mechanisms may work acutely but may fail to protect the brain during chronic deprivation of $\mathrm{TH}(9)$. On the other hand, even during the decrease of serum T4 some brain regions or cell types, but not others, are capable of maintaining T3 levels, what raises the concept of region-specific compensation to low serum TH (9). The developing brain has a very limited capacity to compensate for low $\mathrm{TH}(9)$.

Friesema and cols. were the first to report patients with resistance to $\mathrm{TH}$ due to a transporter defect (4). The authors reported mutations in MCT8 in five young boys aged 1.5- 6 years with severe psychomotor retardation and strongly raised serum T3 concentrations. These patients were characterized clinically by severe proximal hypotonia, poor head control, lack of verticalization, no targeted grasping, involuntary writhing movements, movement-induced increase in distal muscle tone, and severe mental retardation with lack of speech development and rudimentary communicative skills. This group of patients did not show any sign or symptom of hypothyroidism. Their thyroid laboratory evaluations showed serum levels of $\mathrm{T} 4$ and free $\mathrm{T} 4$ at the lower limit of the normal range, TSH concentrations varying from normal to high and remarkably increased serum T3. The five patients harbored loss-of-function mutations of the X-linked MCT8 gene (4).

The neurologic characteristics of our patient have been described in association to inactivating mutations of $M C T 8$, specially the substitution of global hypotonia for a global hypertonia. Schwartz and cols., studying six families with Allan-Herndon-Dudley syndrome stated that the progression to spastic paraplegia is notable (7). During infancy and early childhood the main neuromuscular findings are hypotonia and decreased muscle mass, affecting specially the neck. Truncal hypotonia persists into adolescence and adult life whereas the limbs, hands, and feet become hypertonic, spastic, and contracted, and/or dystonic and fixed in position (10). At this point a neurologic exam may identify hyperreflexia at the large joints, clonus, and Babinski signs (7). With respect to the crisis observed in our patient, they seem to be common in patients with the syndrome and are classified by some authors as paroxysmal kinesigenic dyskinesias that may be provoked by stimuli like changing clothes or diapers (11).

We observed that the growth of our patient, who was born with normal length $(51 \mathrm{~cm})$, was normal during the first 20 months of age. These data were also reported by others and suggest that MCT8 is not impor- 
tant for TH transport in bone cells $(7,12,13)$. Similarly, the patient evaluated by Herzovich and cols. grew normally during the first two years of life, and his bone maturation was advanced (bone age was 30 months when his chronologic age was 18 months) (14). In agreement with these results, the study of Williams and cols. identified that although MCT8 mRNA is expressed in chondrocytes, osteoblasts and osteoclasts at all stages of cell differentiation, T3 availability during skeletal development seems to be limited by D3-mediated catabolism rather than by MCT8-mediated cellular uptake or D2-dependent T3 production (1). The advanced bone maturation is one characteristic of hyperthyroidism in children and adolescents. Therefore the increased bone maturation identified by Herzovich and cols. suggests that the inactivation of MCT8 and the consequent increase of serum T3 creates a hyperthyroid-like state for bone tissue (14).

We also noted a disproportion between the height and the weight of our patient. This disproportion was characterized by superior height in relation to his weight as exemplified by the discrepancy between the height and weight SDs at the ages of 9 months $(+0.89$ and -0.36 , respectively), and 20 months $(+0.33$ and - 1.82, respectively). In the six families with Allan-Herndon-Dudley Syndrome studied by Schwartz and cols. the authors observed that in 19 out of 29 male patients $(65.5 \%)$ at all ages the weight percentile was below the third percentile (7). Herzovich and cols. found increased levels of muscle metabolism markers (serum ammonium and lactic acid) in their patient with inactive MCT8 (14). Aiming to evaluate the influence of serum $\mathrm{T} 3$ on the body mass index Wémeau and cols. studied the effects of treatment with propylthiouracil (PTU) $(200 \mathrm{mg} /$ day) in an undernourished 16 year-old boy with a loss of function mutation of MCT8 (15). After a period of treatment with PTU levothyroxine was added to the treatment at doses of 50,75 , and $100 \mu \mathrm{g} /$ day (15). While treatment with PTU alone reduced free T4, normalized free T3, and increased TSH serum levels, the introduction of levothyroxine, especially in the 100 $\mu \mathrm{g} /$ day dose, allowed TSH and free T4 levels return to those levels obtained before the introduction of PTU (15). More importantly, this strategy improved body mass index as a consequence of the increase in the rate of weight gain from $200 \mathrm{~g} /$ year to $3 \mathrm{~kg}$ /year (this treatment had no effect on cerebral disturbances and the psychomotor retardation) (15). Thus we can speculate that increased serum T3 also generates a hyperthyroid- -like state in the muscle and adipose tissue, capable of preventing the adequate weight gain.

In our patient the normal lipid profile in spite of low total and free serum T4 levels suggests an increased action of $\mathrm{T} 3$ in the liver. We can speculate that the increased action of $\mathrm{T} 3$ in the liver hindered the elevation of serum LDL and triglyceride that could be expected in the context of hypothyroidism. Interestingly, serum levels of sex hormone-binding protein, a protein synthesized in the liver under the stimulus of $\mathrm{TH}$, was persistently elevated in the patient described by Herzovich and cols. (14).

The patient we have described, like other patients with inactivating mutations of MCT8, had no signs or symptoms typically associated to congenital hypothyroidism (prolonged jaundice, umbilical hernia, bradycardia, growth retardation, myxedema and tendency to overweight or obesity) (12). This clinical finding reinforces the concept that tissues like bone, fat and liver are not as dependent on MCT8 for TH transport as the brain is.

In our patient, and also in those described by other authors, the high serum values of TSH associated to high serum T3 suggest that the negative feedback of $\mathrm{T} 3$ on the pituitary is compromised probably because a smaller amount of T3 is capable to reach its nuclear receptors. Maranduba and cols. studied four adult Brazilian patients of the same family and showed that the protein originated from the mutated MCT8 has a low capacity to promote T3 transport into the cells (16). This finding may have severe consequences to the brain, a tissue which is very dependent on MCT8 for T3 transport into cells. It is noteworthy that the introduction of levothyroxine resulted in reduction of T3 and TSH serum levels. We believe that the effect of levothyroxine may be attributed to a better pituitary negative feedback capable of reducing TSH secretion and consequently the conversion of T4 to T3. We must remember that in the pituitary almost three quarters of intracellular $\mathrm{T} 3$ originates from the conversion of $\mathrm{T} 4$ and the remainder derives from circulation. However, alterations in thyroid profile associated to mutations in MCT8 are still a reason for debate. Maranduba and cols. identified that the increase of serum T3 is related to the reduction of its intracellular clearance as a result of decreased entry of the hormone into cells that metabolize it through D3 (16). However, studies in Mct8 knockout mice show that $\mathrm{T} 3$ generation by $\mathrm{Dl}$ and $\mathrm{D} 2$ is increased, which has a consumptive effect on serum 
total and free T4 levels. In these mice pituitary resistance to T3 was also identified (15).

In our patient the novel mutation 630insG in the coding region at exon 1 of MCT8 resulted in a frameshift with truncation of the protein at codon 240 . Probably the mutation 630insG inactivated MCT8 completely. As the insertion was not observed in 50 healthy control men polymorphism was excluded. The functional effect of this novel mutation has still to be determined. On the other hand, Frints and cols. reported a similar mutation 630insA in one among the 13 families studied with individuals affected by X-linked mental retardation (17). Mutation 629insA caused a frameshift in exon $\mathrm{l}$ and introduced a premature termination codon in exon 2 of MCT8 (17). The mutations of MCT8 encompass large deletions, smaller frameshift deletions, deletions or insertions of 1 -amino acid, nonsense mutations and missense mutations (2). Studies suggest that there is a genotype-phenotype correlation in patients with mutations in MCT8 (2).

Our patient evolved with variable levels of antithyroid antibodies. Both thyroglobulin and thyroperoxidase antibodies were detected at the age of 9 months and again when he was older than 8.3 years. One male patient with inactivating mutation of MCT8 described by Dumitrescu and cols. had been diagnosed with insulin-dependent diabetes mellitus at 3 years of age, and the patient had a maternal aunt, an uncle and one grandmother with autoimmune thyroid disease, evidenced by positive thyroglobulin and thyroperoxidase antibodies (5). The other patient studied by the same group had a maternal grandfather with mild TSH elevation due to autoimmune thyroid disease confirmed by positive thyroperoxidase antibodies (5). We believe that current knowledge does not allow us to associate the inactivation of MCT8 to the risk of autoimmunity. Probably the description of new patients with inactivation of MCT8 and a deeper understanding about MCT8 functions and interactions will help in this matter.

The mother of the patient is heterozygous for the mutation of MCT8 and, although clinically asymptomatic, showed mild thyroid function abnormalities (normal serum TSH and total T4, serum T3 in the upper limit of normality and low free T4). Abnormal thyroid profile with high serum T3 levels may be present in 25\% of female carriers of the MCT8 mutation (17). Studies performed by Dumitrescu and cols. to clarify the reason for the thyroid phenotype in heterozygous women suggested that both dominant-negative effect and ha- ploinsufficiency are mechanisms responsible for the dominant expression of the thyroid phenotype (5). The authors observed that apparently there is no preferential $\mathrm{X}$ inactivation of the two alleles (5). The phenotype of heterozygous females for mutations of MCT8 encompasses from asymptomatic patients to those with mild mental retardation $(5,14,17)$. However, Frints and cols. reported the first female patient with the Allan-Herndon-Dudley syndrome (17). This patient was severely developmentally retarded and showed elevated serum $\mathrm{T} 3$ and free $\mathrm{T} 3$ due to a de novo balanced $46, \mathrm{X}, \mathrm{t}(\mathrm{X} ; 9)$ (q13.2;p24) translocation (17). In this patient the complete nonrandom inactivation of normal X chromosome impinged the expression of MCT8 (17).

Although new cases of mutations of MCT8 have been described, the scarce number of patients precludes knowledge about prevalence, clinical manifestations and genotype-phenotype correlation of the disease. X-linked mental retardation has an estimated prevalence of $0.1 \%$ in males and is related to disturbances in a group of 82 genes, including MCT8 (2). Currently, in view of the difficult clinical definition of X-linked mental retardation, it is suggested that mutations of MCT8 be suspected in the context of an abnormal thyroid profile characterized by increased $\mathrm{T} 3$, low-normal to low free T4, low rT3, and normal to elevated TSH serum levels (2). The measurement of serum free T3 is considered the better method for screening high-risk populations, such as children with developmental delay and hypotonia $(7)$.

In summary, we describe a male patient with a novel inactivating mutation of MCT8. The patient was characterized clinically by severe neurologic impairment (initially manifested as global hypotonia later evolving with generalized hypertonia and spastic quadriplegia), normal growth during the first two years of life, reduced weight gain during his infancy and childhood and absence of the typical signs and symptoms of hypothyroidism. His laboratory evaluations disclosed high T3, low total and free T4, and mildly elevated TSH serum levels. Treatment with levothyroxine resulted in better thyroid function tests (with normalization of total T3 and TSH, a progressive increase in free T4, and the maintenance of low total T4 levels) but no clear clinical benefit could be recognized. Our results reinforce the concept that the role of MCT8 in the intracellular transport of $\mathrm{TH}$ is tissue-dependent: neurons seem to be highly dependent on MCT8, while the bone, adipose tissue, muscle and liver are clearly less dependent on 
MCT8 and may therefore suffer the consequences of the exposition to high serum T3 levels.

Acknowledgements: We thank Professor Theo Visser for evaluating the sequence of MCT8 gene and for encouraging us to study this novel mutation.

Disclosure: no potential conflict of interest relevant to this articlewas reported.

\section{REFERENCES}

1. Williams AJ, Robson $\mathrm{H}$, Kester MHA, van Leeuwen JPTM, Shalet SM, VisserTJ, et al. lodothyronine deiodinase enzyme activities in bone. Bone. 2008;43:126-34.

2. Friesema ECH, Visser WE, Visser TJ. Genetics and phenomics of thyroid hormone transport by MCT8. Mol Cell Endocrinol. 2010;322:107-13.

3. Friesema EC, Ganguly S, Abdalla A, Manning Fox JE, Halestrap AP, Visser TJ. Identification of monocarboxylate transporter 8 as a specific thyroid hormone transporter. J Biol Chem. 2003;278(40):128-35.

4. Friesema EC, Grueters A, Biebermann H, Krude H, von Moers A, Reeser $\mathrm{M}$, et al. Association between mutations in a thyroid hormone transporter and severe $X$-linked psychomotor retardation. Lancet. 2004;364:1435-7.

5. Dumitrescu AM, Liao XH, BestTB, Brockmann K, Refetoff S. A novel syndrome combining thyroid and neurological abnormalities is associated with mutations in a monocarboxylate transporter gene. Am J Hum Genet. 2004;74:168-75.

6. Friesema ECH, Kuipe GGJM, Jansen J, Visser TJ, Kester MHA. Thyroid hormone transport by the human monocarboxylate transporter 8 and its rate-limiting role in intracellular metabolism. Mol Endocrinol. 2006;20:2761-7.

7. Schwartz CE, May MM, Carpenter NJ, Rogers RC, Martin J, Bialer $M G$, et al. Allan-Herndon-Dudley syndrome and the monocarboxylate transporter 8 (MCT8) gene. Am J Hum Genet. 2005;77:41-53.
8. Miller SA, Dykes DD, Polesky HA. A simple salting out procedure for extracting DNA from human nucleated cells. Nucleic Acids Res. 1988;16(3):1215.

9. Sharlin DS, Gilbert ME, Taylor MA, Ferguson DC, Zoeller RT. The nature of the compensatory response to low thyroid hormone in the developing brain. J Neuroendocrinol. 2010;22:153-65.

10. Holden KR, Zúñiga OF, May MM, Su H, Molinero MR, Rogers RC, et al. X-linked MCT8 gene mutations: characterization of the pediatric neurologic phenotype. J Child Neurol. 2005;20:852-7.

11. Brockmann K, Dumitrescu AM, Best TT, Hanefeld F, Refetoff S. X-linked paroxysmal dyskinesia and severe global retardation caused by defective MCT8 gene. J Neurol. 2005;252:663-6.

12. Biebermann $H$, Ambrugger $P$, Tarnow $P$, von Moers $A$, Schweizer $U$, Grueters A. Extended clinical phenotype, endocrine investigations and functional studies of a loss-of-function mutation A150V in the thyroid hormone specific transporter MCT8. Eur J Endocrinol. 2005;153:359-66.

13. Namba N, Etani Y, Kitaoka T, Nakamoto Y, Nakacho M, Bessho K, et al. Clinical phenotype and endocrinological investigations in a patient with a mutation in the MCT8 thyroid hormone transporter. Eur J Pediatr. 2008;167:785-91.

14. Herzovich V, Vaiani E, Marino R, Dratler G, Lazzati JM, Tilitzky S, et al. Unexpected peripheral markers of thyroid function in a patient with a novel mutation of the MCT8 thyroid hormone transporter gene. Horm Res. 2007;67:1-6.

15. Wémeau JL, Pigeyre M, Proust-Lemoine E, d'Herbomez M, Gottrand $F$, Jansen $T$, et al. Beneficial effects of propylthiouracil plus I-thyroxine treatment in a patient with a mutation in MCT8. J Clin Endocrinol Metab. 2008;93:2084-8.

16. Maranduba CMC, Friesema ECH, Kok F, Kester MHA, Jansen J, Sertié $A L$, et al. Decreased cellular uptake and metabolism in Allan-Herndon-Dudley syndrome (AHDS) due to a novel mutation in the MCT8 thyroid hormone transporter. J Med Genet. 2006;43:457-60.

17. Frints SG, Lenzner S, Bauters $M$, Jensen LR, Van Esch $H$, des Portes $\mathrm{V}$, et al. MCT8 mutation analysis and identification of the first female with Allan-Herndon-Dudley syndrome due to loss of MCT8 expression. Eur J Hum Genet. 2008;16:1029-37. 